\title{
Full Packaged Learning Solutions for Studying Mathematics at School
}

\author{
Vyacheslav V. Utemov ${ }^{1 *}$, Rezeda M. Khusainova ${ }^{2}$, Marina G. Sergeeva ${ }^{3}$, Victor A. Shestak ${ }^{4}$ \\ ${ }^{1}$ Vyatka State University, Kirov, RUSSIA \\ ${ }^{2}$ Kazan (Volga region) Federal University, Kazan, RUSSIA \\ ${ }^{3}$ Peoples' Friendship University of Russia (RUDN University), Moscow, RUSSIA \\ ${ }^{4}$ MGIMO-University, Moscow, RUSSIA
}

Received 23 May 2018 • Revised 5 July 2018 • Accepted 15 August 2018

\begin{abstract}
The speed of modern changes in the system of teaching reflects an unprecedented accelerated renewal of means, forms and methods of teaching. Today, it is very important to test new learning solutions that reduce teachers' time on organization of students' educational activities. The idea of solving this problem is to combine the theory and practice of taking managerial actions and pedagogy in order to identify the type of learning solutions that reduce teachers' time, in particular teachers of mathematics, to prepare for classes. Thus, the purpose of the article is to justify full packaged learning solutions as an effective means of reducing the time spent on organizing the educational activities of schoolchildren. The authors of the article have determined the full packaged product as a package of program-methodical and subject-developing support that can be used by consumers of educational services (children, parents, teachers, administrators, employers) for independent use (a turn-key project). The leading methods of research are monitoring the organizational activities of teachers during math lessons, talking to teachers, analyzing methodical work and teachers' profiles, modeling and statistical processing of research results. As a result of the 2016-2017 experiment, where 21 teachers of mathematics took part, the authors of the article have defined types of learning solutions for mathematics teachers (adjustable, integrated and packaged); have described the stages of development and phases of creating a full packaged learning solution. Evaluation of the effectiveness of using full packaged product allowed to make a conclusion about an average decrease of time costs by $22 \%$ while preparing for classes. The theoretical significance of the article is due to the contribution to the development of scientific ideas about the means of methodical support for teachers of mathematics. The practical use of the proposed methods allows to organize a step-by-step transition from the development of adjustable solutions to full packaged learning solutions for studying school mathematics that contribute to reducing teachers' time spent on the organization of educational activities of students. The value of the full packaged product is justified with the help of a "project triangle", which connects key parameters for assessing the effectiveness of providing methodical support to mathematics teachers: the amount of work, time and costs. Changing the value of one parameter leads to changes of the values of others. Full packaged product allows to balance these parameters and achieve the planned educational result.
\end{abstract}

Keywords: full packaged learning solutions, math teaching tools, types of learning solutions, phases of creating full packaged learning solutions, stages of development of full packaged learning solutions

(C) 2018 by the authors; licensee Modestum Ltd., UK. This article is an open access article distributed under the terms and conditions of the Creative Commons Attribution License (http://creativecommons.org/licenses/by/4.0/).

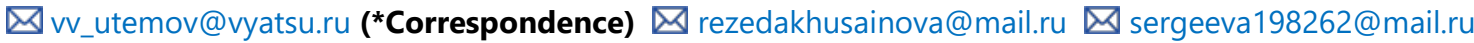




\section{Contribution of this paper to the literature}

- The research has differentiated 3 types of learning solutions for mathematics teachers: adjustable, integrated and full packaged learning solutions. Learning solutions are aimed to achieve the specified results of teaching mathematics (the acquisition of knowledge, skills, competencies, etc.) by a specific target group.

- The educational marketplace of mathematics is proposed to be supplemented with a separate component full packaged learning solutions. They should be considered as a package of program-methodical and subject-development support of the educational process.

- The paper has described peculiarities of the development of full packaged learning solutions: stages of the learning solution development and phases of creating full packaged learning solutions that can be used for step-by-step transition from the adjustable solutions to full packaged learning solutions for the study of school mathematics. These learning solutions contribute to reducing the time spent by teachers on organizing educational activities of students.

\section{INTRODUCTION}

\section{Relevance of the Research}

The current educational system in Russia differs from the previous Soviet system by at least two key facts. First, according to Bordovsky (2012), is deideologization, which has destroyed the existing system of education based on well-known moral precepts. Secondly, according to the results of the study of the Russian Academy of Education, it should be noted that children's mentality and value orientations have changed, accompanied by acceptance of alien behavior patterns in Russia, inability to focus on certain activities, lack of expressed interests, absentmindedness, and hyperactivity (Feldshtein, 2010; Shaidullina et al., 2015).

All this initiates intrasystem and outside system challenges to the modern education system. Intrasystem calls are associated with a change in the social request:

- the demand for "hybrid" specialists: teacher-tutors, integrator educators, engineering workers, business engineers;

- increased attention to safety and health of students: health education, universal inclusive education;

- "digital" children: children educate their parents; education through activities in the environment;

- ensuring the effectiveness of school activities: the growth of requirements to the quality of education.

Outside system calls formulate external subjects in relation to the education system (Reimagining the Role of Technology in Education, 2017):

- individualized learning: non-systemic education (online education); development of educational services; global public education environment;

- growth in the demand for adult education ("lifelong learning");

- increased requests for participation in the management of children's education by parents;

- mass introduction of innovations (network forms of education, use of distance learning, expansion of professional and public participation).

These facts and challenges are reflected in the increasing complexity of the teacher's work. The complexity leads to an increase in time to prepare for classes. However, it should be noted that in pedagogical science there has always been the question of finding low-cost means of methodical support for teachers to achieve educational results of students. Means of methodical support can be disclosed through the concept of "learning solution".

A learning solution is a product or service that implements a complex task of achieving specified learning outcomes in mathematics (acquisition of knowledge, skills, competencies, etc.) by a specific target group.

Learning solutions can be based on the use of information and communication technologies. However, an analysis of the impact of information and communication technologies on the quality of education based on the results of the 2015 survey shows a possible re-evaluation of digital teaching aids (OECD, 2015). Among the reasons can be: the lack of a strategy for their implementation in the learning environment, the concept of their use from the standpoint of psychological and pedagogical science and the poor quality of educational software. Therefore, the subject of this article are: learning solutions aimed to improve empirical learning, developing project and research pedagogy, promoting practical activities and joint learning; and solutions that provide a real-time formative assessment. 
Traditional learning solutions are adjustable solutions. They usually do not exist in a ready-to-use form. Adaptation, specifics of their use, competence of the teacher can change the decision completely. Adjustable solutions are: software and methodical materials (sample programs, abstracts, tests, developments, etc.), subjectdeveloping tools (didactic games, cards with tasks), analogs (work experience of others) and experimental work (samples).

Recently, an integrated learning solution is being singled out. It is a complex solution that includes several interrelated adjustable learning solutions for mathematics of full-time, remote and other formats.

From observations of organizational activities of mathematics teachers and conversations with them, we can note that the educational marketplace of the mathematics lesson is filled with adjustable and integrated learning solutions, and the quality of the educational results can have a probabilistic nature. These learning solutions today are quite costly in time while preparing for math lessons.

A new type of educational solutions for methodical support of teachers is required, which would meet modern requirements and guarantee minimal time. Thus, a full packaged learning solution can be considered as a package of program-methodical and subject-developing support that can be used by consumers of educational services (children, parents, teachers, administrators, employers) for independent use ("turn-key").

Thus, learning solutions are aimed to solve the methodical task of achieving the specified learning outcomes for mathematics (the acquisition of knowledge, skills, competencies, etc.) by a specific target group. Existing types of learning solutions should be reviewed and among them a separate component of the educational marketplace should be singled out - full packaged product solutions with increased reliability of achieving the educational result. The purpose of this research is to justify full packaged product solutions as an effective means of reducing the time spent on organizing the educational activity of schoolchildren. Therefore, the objectives of the study are: analysis and systematization of existing types of learning solutions; evaluation of the effectiveness of existing types of learning solutions; allocation of a full packaged solution as a separate type of learning solution; description of the main stages of development and phases of the creation of full packaged product solutions; experimental study of the effectiveness of using this solution.

\section{LITERATURE REVIEW}

\section{Analysis of Russian Scientific and Pedagogical Literature}

Studies in the Russian scientific and pedagogical literature on the transformation of methods accompanying the professional activity of subject teachers, including mathematics teachers, are quite scattered. Recently, the competence approach as a tool for managing human resources of the organization, including educational ones, has become quite popular. If there is a large number of diverse activities and a limited number of competent personnel in an organisation, it leads to a shortage of skills and increased costs due to violation of the timing and the need to attract additional resources (Kvon et al., 2017). So there is a dependence of organizations on key specialists, especially if the work is complex or narrow-profile, for example teachers of the exact sciences.

Trunovich and Shlygin (2008) consider a full packaged solutions as a removal of this organizational problem aimed to introduce funds that ensure the professional activity of workers. Vinogradova and Galimova (2017) conduct an econometric analysis of the organizational information system at Russian enterprises, considering the concept of a "full packaged solution" as an alternative to a solution that takes into account the specific nature of the particular organization that is most time-consuming and finance. Some authors identify full packaged product with a new stage in the development of technologies - ready-made, used and available technologies (Zolotov, 2013). On the other hand, rapid development of information and communication technologies in organizations isolates a group of universal tools called full packaged product solutions (Beryoza, 2012). At the same time, Bokova (2006) concludes that the problematic issues arising in the development of a complex solution in the form of a full packaged solution decrease the cost of individual settings, but do not exclude them completely. Considering the increasing complexity of presenting educational material on mathematics from the degree of readiness for its perception by students, this conclusion allows to confirm the importance of the level of teacher"s professionalism.

\section{Analysis of Foreign Studies}

In foreign studies, full packaged solutions are viewed as a means of personalized learning. The psychologist Bloom (1984) has described a phenomenon known as two-sigma (two curves of the normal distribution of students' results), which means that an ordinary student, taught individually under an individual program, shows results 98\% higher than a control group taught by standard methods. Personalization of learning can be manifested in attributes of the learning process: objectives of learning, learning approaches, educational content, its sequence, pace of presentation, presentation forms. Attributes can be described as a learning solution (Reimagining the Role 
of Technology in Education, 2017). Learning solutions allow less successful students to provide access to educational material of more complex level, more complex kinds of activity, as they are offered a methodologically developed algorithm for mastering this material (Lave \& Wenger, 1991; Molnar, 2014). Education, built using a set of learning solutions, allows students to develop less time-consuming skills in making meaningful choices about their learning and form the basis for continuous, independent learning (Bandura, 2001). Spitzer and Aronson (2015) emphasize that an effective form of students' assistance in school is significant for the development of their personality and, for example, can increase internal motivation and academic involvement. Academic involvement can be a condition for reducing the disparity in the level of education in the classroom, including work with a class with a different level of mathematical readiness, which can allow teachers to become co-learners with their students, creating a new experience for in-depth study of content. This expanded learning experience is John Dewey's (1937) idea of creating "more mature students".

The full packaged product solution proposed by Fiallo and Gutiérrez (2017) provides the study of evidence in trigonometry in a software environment with dynamic geometry in 10th form. Another example of the full packaged solution is a system that can automatically configure the optimal learning route for students on a set of loaded learning materials (Govindarajan, Kumar \& Kinshuk, 2017). Sommer et al. (2014) in their works describe the online system of recommendations for e-learning in engineering education, which can also be designated as a full packeged solution. A number of project interactive learning solutions can also be considered as full packaged solutions (Viel et al., 2015). Also, there are integrated learning solutions for the study of combinatorics in elementary school: thus, a learning solution with the use of level abstraction and the selection of various decision strategies allows to influence the increase in the level of mastering of combinatorics in primary school students (Herzog, Ehlert, \& Fritz, 2017).

Durkin, Star, and Rittle-Johnson (2017) prove the increase in the effectiveness of learning solutions from the addition of a package of software and methodical support to the system of additional methodical support for the teacher in making a decision on the management of conceptual and procedural knowledge of students. Conclusions of the scientists show that methods of solving the same learning problem were particularly effective if the students supported procedural flexibility and supported the conceptual and procedural knowledge of the students, expressed in the form of educational recommendations for the teacher. The effectiveness of learning solutions also depends on the availability of a feedback system (Swacha, 2017).

Another confirmation of the growth in the effectiveness of learning solutions in the transition from adjustable to full packaged solutions can be found in the works of Dover, Manwan, and Munn (2018). They prove the effectiveness of the transition to a common open educational course from a personalized educational course.

The importance of ready-to-use "turn-key" learning solutions is also emphasized for the organization of extracurricular activities for children. So, the demand for extracurricular educational products and services is growing, including teaching aids, early learning materials, educational websites and private education (Scanlon \& Buckingham, 2004). Another example of the importance of full packaged solutions can be the results of the research, which show that in the commercial market of manufacturers of learning solutions, a large proportion of organizations focused on the development of integrated learning solutions (Niemelä, Isomöttönen, \& Lipponen, 2016).

The problems of adjustable learning solutions are also discussed in the evaluation of economic efficiency based on the results of their implementation. Thus, learning solutions for video training from various providers were used, but were not adopted in secondary schools on a larger scale due to financial implications and less relevance of content. It naturally led to a solution close to a fuull packaged product - solutions focused on cloud-based educational video content (Matad, Srinivasa, \& Fernandes, 2016).

Jensen and Frimodt-Møller (2015) provides an integrated learning solution based on IT technology for teaching the art of music. The integrated solution demonstrated on the tablet and proposed by the developers, also includes tools that help the musician in the process of rehearsal.

Convenience of use as a characteristic of learning solutions is frustrated in digital learning. A high degree of ease of use allows teachers to focus on their main task - teaching. Kenttälä et al. (2015) describe the results of a study on the ease of use of digital learning solutions and show the differences that are observed between different types of learning solutions for digital learning (Hoffmann, 1999). Also, the complex of technological and pedagogical support when implementing the solution in mixed training improves the quality of the training (Carapina et al., 2015; Doolan \& Guiza, 2015). Learning solutions for digital learning can be used to improve the motivation of students and the growth of their academic performance. The results of Heider (2015) are based on the development of WileyPLUS Learning Space. The study included an in-depth study of changes and challenges associated with learning, including new requirements and expectations of students, administrators, politicians and others in the field of education. Other studies show that the use of a learning manual and a model system even for complex skilled tasks also shows its effectiveness (Akpinar, 2012; Payne et al., 2009). 


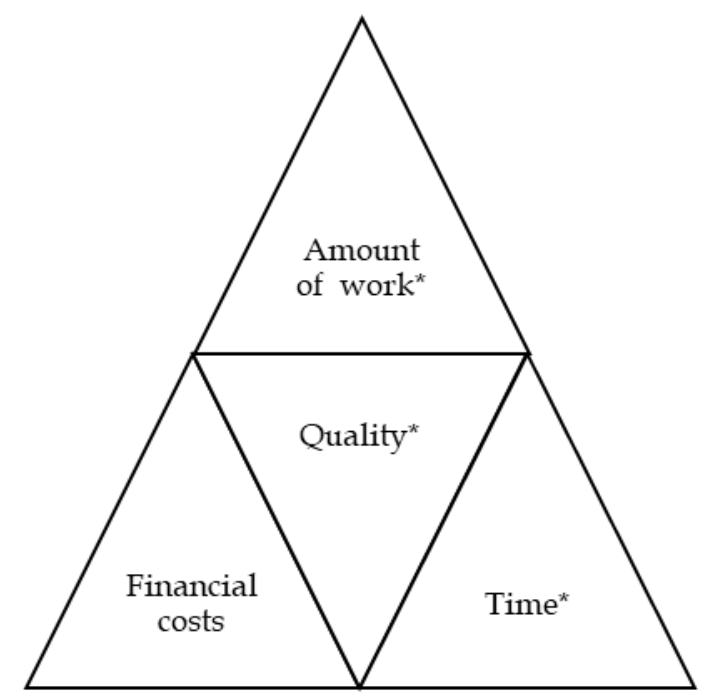

Figure 1. Performance indicators for adjustable learning solutions

Thus, transformation of methodical tools, which are generalized and proposed for accompanying the professional activity of the mathematics teacher is of great interest. However, well-known sources describe either disparate results of learning solutions, or extremely narrowly specialized questions related to information means of teaching in math lessons. Modern schools, however, require low-cost time-consuming tools to support math teachers in order to achieve the planned educational outcomes of students.

\section{MATERIALS AND METHODS}

\section{Theoretical Basis of the Research}

Theoretical basis of the research is the development of full packaged product solutions and their implementation in the lessons of mathematics as one of the effective ways to reduce the time spent on preparing for classes. In the scientific literature, the term "learning solution" refers to a product or service that implements a complex task of achieving specified learning outcomes (the acquisition of knowledge, skills, competencies, etc.) by a specific target group. A set of learning solutions, which are systematized for the selection and combination of forms of learning tasks, is an educational marketplace.

Here and further indicators of the effectiveness of learning solutions are presented in the form of a triangle. The starting indicators are the vertices of the triangle and define its outline. The resulting indicator is quality, it is delineated after the implementation of the learning solution within the established framework. The symbol "*" in the figures means indicators, which are characterized by a high share of uncertainty of the final value for the indicated type of learning solution. The proposed visualization of results in the form of a triangle can be convenient for understanding the focal indicators of the effectiveness of the activity. Here we adhere to the paradigm of projectoriented management, which uses the notion of a "project triangle".

Let's imagine that the main result of implementing a learning solution - the quality of the educational results of students in mathematics - depends on such resources as the amount of work, financial costs, time (Figure 1).

Let's get the minimum financial costs for the acquisition and implementation of an adjustable training solution. Time costs will be undefined due to the need to configure this solution for specific conditions and, as a result, the scope of work on the implementation of the solution is also not defined. Therefore, the quality of educational outcomes of students, stated by the developer of the learning solution, will be of a probabilistic nature. Approbation of an adjustable solution is the only way to determine exactly whether this solution will be effective under specific conditions.

A more sophisticated means of reducing teachers' time costs in teaching mathematics is an integrated learning solution - a comprehensive solution that includes several interrelated learning solutions for full-time, remote and other formats. Complication occurs due to the use of a set of learning solutions. This complex takes into account continuity of implemented solutions in math lessons, but does not remove the indicated difficulties inherent in adjustable solutions. 


\section{Methods of Research}

We used the following methods to identify full packaged learning solutions that characterized by teachers' low educational expenses: the modeling, monitoring the organizational activities of teachers in math lessons, talking to teachers, analyzing the methodical development of teachers, questioning teachers and statistical processing of pedagogical experiment data.

\section{Experimental Research Base}

Approbation, synthesis and implementation of the research results are carried out on the basis of four schools of the Kirov region - regional innovation sites supervised by the Vyatka State University, where an experimental study was conducted to evaluate the effectiveness of using full packaged learning solutions (2016-2017):

- by conducting an experienced teaching of mathematics in 5-9 grades of the main school by 21 math teachers on the developed full packaged learning solutions: methods for conducting lessons in mathematics with a robotic designer and using tasks that involve calculating and measuring exercises with a set of calculating and measuring equipment (more than 80 students annually);

- discussion of methodical aspects within the framework of seminars and round tables with teachers of mathematics of the Kirov region within the framework of the advanced training courses at the Vyatka State University (60-70 participants annually);

- in the form of reports and speeches at scientific conferences and seminars of various levels, including international ones, publications in collections of scientific articles and scientific and methodical periodicals.

\section{Stages of Research}

The research had four stages.

At the first stage, we studied the state of the problem in the theory and practice of teaching pupils to mathematics in the primary and secondary schools. For this, we carried out the study and analysis of psychological, pedagogical and methodical literature on the problem of research (not only in mathematics, but also in other school disciplines); made observation, interviews and analysis of the experience of teachers of mathematics and methodists in order to study possible ways of reducing the methodical load of teachers and increasing the quality of obtaining educational results on the subject of mathematics.

At the second stage, we developed methodical approaches in order to generalize the means of methodical support to significantly reduce the time spent in preparing for math classes; systematized types of learning solutions; discussed the results of the generalization during the reports at conferences and seminars of various levels on the methodology of teaching mathematics.

In parallel with the second, the third stage is being implemented, during which an experiment was conducted. It involved 21 math teachers from four schools of the Kirov region - regional innovation sites supervised by the Vyatka State University. Teachers were invited to apply full packaged learning solutions at lessons. After the questionnaire was conducted and the analysis of its results was carried out.

The fourth stage was generalisation of the experience on creation and development of full packaged learning solutions. We defined main stages of development and phases of creating full packaged learning solutions for their gradual introduction into the pedagogical practice of studying maths at school.

\section{RESULTS}

\section{Full Packaged Learning Solutions in Mathematics}

In our opinion, full packaged learning solutions, which are intended for methodical support of teachers both in the classroom and in extra-curricular activities in mathematics, are different from the means currently used to reduce teachers time spent on preparations for the lesson. A full packaged learning solution can be defined as a package of program-methodical and subject-development support that can be used by consumers of educational services (children, parents, teachers, administrators, employers) for independent use in the study of school mathematics (turn-key project).

Full packaged learning solutions are characterized by the simplest implementation procedure: it is enough to follow the steps of the instruction, after which the solution has already been implemented in most cases. Consider performance indicators for full packaged learning solutions. (Figure 2). 


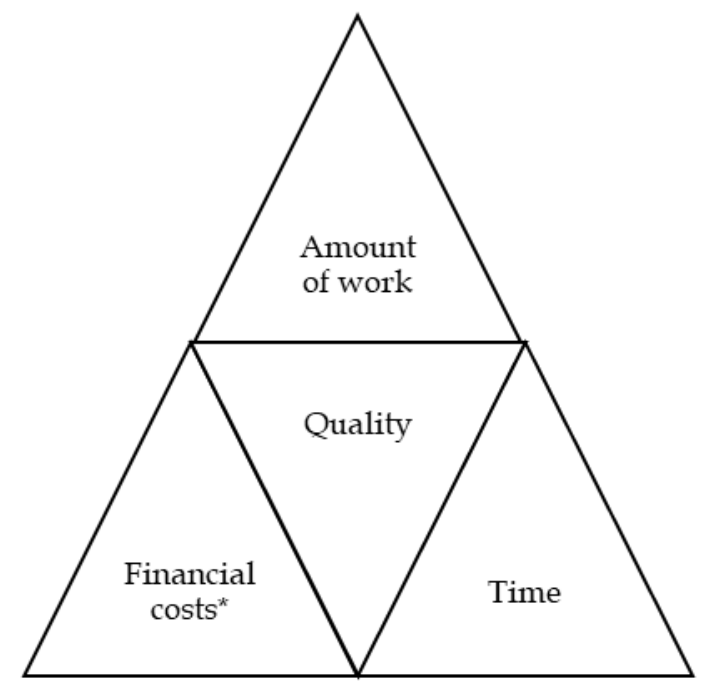

Figure 2. Performance indicators for full packaged learning solutions

Financial costs of acquiring and implementing a full packaged learning solution are in most cases higher than those of adjustable solutions. However, if a full packaged solution determines the great amount of work with the planned time for their implementation, financial costs will be final and, unlike adjustable solutions, these resources will no longer require approbation and adjustment under the conditions. Therefore, as a result, financial costs may be lower than of adjustable solutions. Having the predictable vertices of the triangle (performance indicators), the quality of the educational results of students in mathematics as a result of the introduction is close to the specified solution. Predictability of quality is a key characteristic of a full packaged solution.

For a better understanding of the essence of a full packaged learning solution, we give below examples of types of learning solutions: adjustable, integrated, full packaged.

An example of an adjustable learning solution. Educational robotics in the mathematics class allows students to apply the skills to solve problems, display computational skills and knowledge about geometric figures, numbers, arithmetic operations, quantities, units of measure, ability to solve problems for multiple comparison, for movement. To perform mathematical tasks, students are forced to measure quantities, estimate numerical values for adequate automatic execution of scenarios by the robot-platform, especially with sensors, estimate and recalculate time values. The teacher is provided with a set of educational robotics for use in classes of mathematics in elementary school. The teacher has never used them before and has not applied them in classes. To the set of robotics there is only instruction on connection and technical use of equipment. It turns out that in order to start using the new kit in class, at the beginning the teacher needs to understand himself, to develop the content of classes using equipment. Further to test the effectiveness of these classes and only after that start using in his work with children. It is easy to see the unplanned costs of implementation of the solution: time, scope of work, and perhaps the growth of financial costs associated with the direction of the teacher for training courses. This is an adjustable learning solution.

An example of an integrated learning solution. A teacher of mathematics with educational robotics is provided by the manufacturer an access to an exercise system using a robotic platform in a remote form. Exercises do not intend to immerse children in mathematics. Exercises are aimed to test technical skills to work with the platform. In this case, the expansion of the learning formats and the interconnection of individual learning solutions are presented, but the problems arising for a mathematics teacher, indicated above, still exist. This is an integrated learning solution.

An example of a full packaged learning solution. A teacher of mathematics is provided with a set of educational robotics, and an educational program on the subject of mathematics for a particular class is attached with all the abstracts of classes, handouts and visual material for use in math classes. In addition, the kit provides a specialized program, which helps the teacher to master it. This is a full packaged learning solution.

\section{Development Stages of Full Packaged Learning Solutions in Mathematics}

Any technology in its development goes through several stages. Thus, full packaged learning solutions for studying school mathematics, according to our research, go through three main stages of development: 1) initiation; 2) standard;3) full packaged solution. 


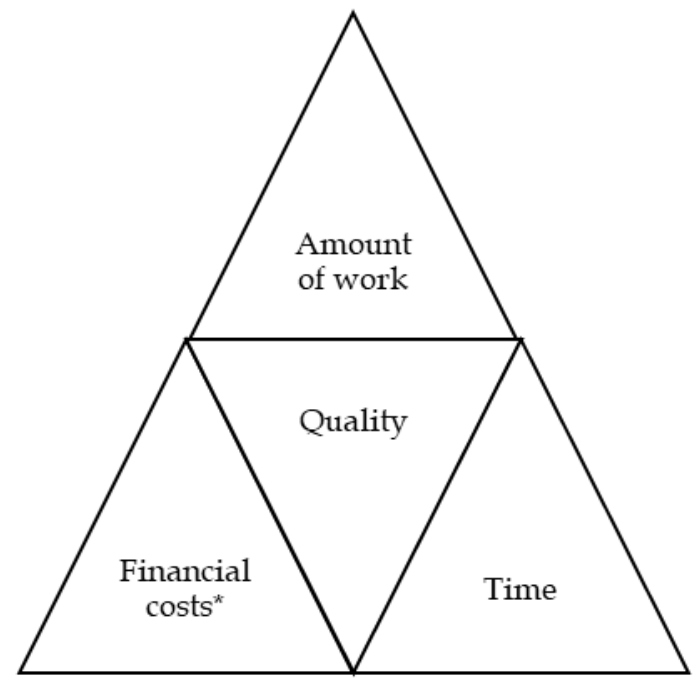

Figure 3. Performance indicators for full packaged learning solutions at the "initiation" stage

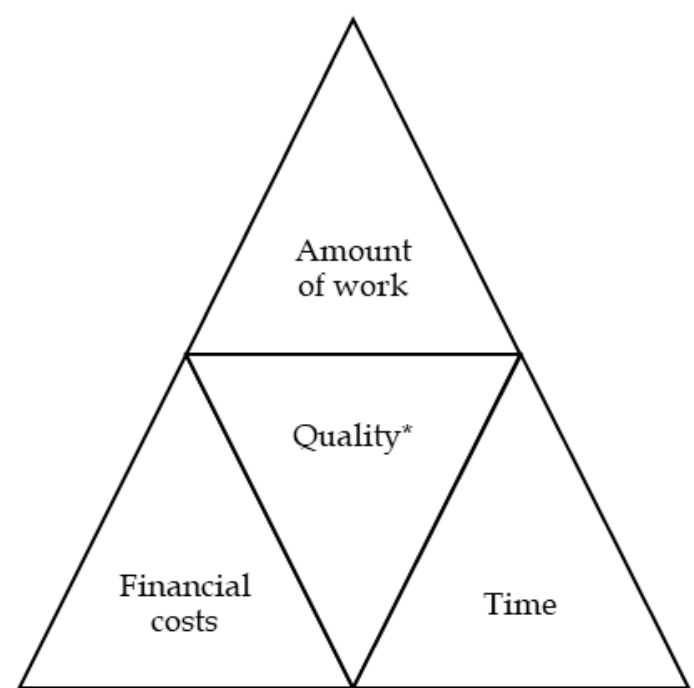

Figure 4. Performance indicators for full packaged learning solutions at the "standard" stage

The first stage of "initiation" is associated with the emergence of the idea of a learning solution. The author has developed a solution and once obtained the desired result. The learning solution is already there, but only one is familiar with it. The quality of the results from the implementation of the learning solution is lacking, as there is no detailed work required, financial and time costs for implementing the solution under conditions that are not identical to the place of trial implementation (Figure 3).

At this stage, the learning solution depends entirely on the performer and conditions of use, therefore, there is no guarantee of predictability of the quality of the result achieved.

If the learning solution starts to use a sufficient number of teachers in the work, then the decision goes to the "standard" stage. In this case, there is a detailed elaboration of the necessary work, financial and time costs for implementing the solution. But the quality of the result achieved depends on the developer of the learning solution, from his experience in implementing this solution (Figure 4).

At this stage, when implementing a learning solution, predictable costs, planned time and quality depend on the developer.

The final stage of development is the "full packaged solution". As soon as the developer is able to present and describe his solution in such a way that each interested teacher without the participation of the developer can implement it and achieve the specified quality, the solution has reached the stage of the "full packaged solution" (Figure 5). 


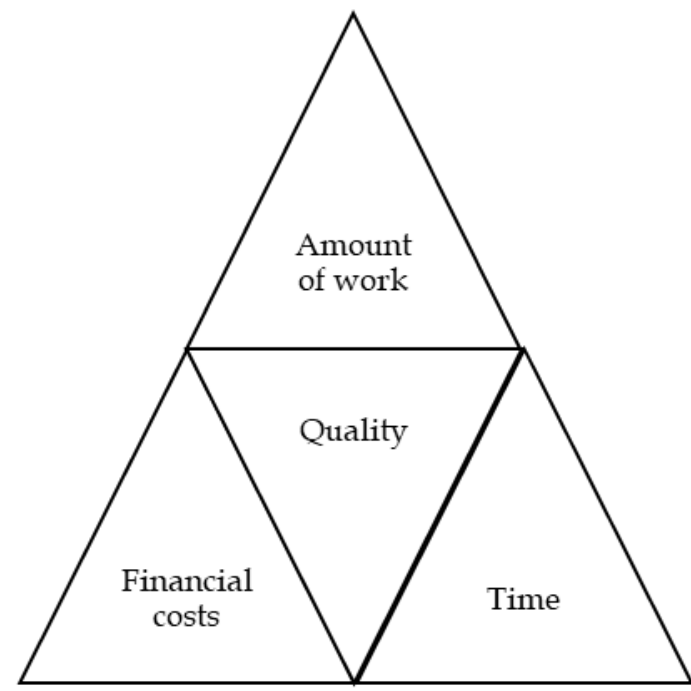

Figure 5. Performance indicators for full packaged learning solutions at the "full packaged solution" stage

Thus, at this stage, predictable costs, planned time and quality do not depend on the developer.

\section{Phases of Creating a Full Packaged Learning Solution in Mathematics}

Consider the life cycle of creating a full packaged learning solution for studying mathematics. Under the life cycle we understand certain phases through which the full packaged learning solution passes in the process of its creation and functioning. This separation is important not only from the theoretical, but also from the practical point of view, because it gives the opportunity to control the process of creating a learning solution.

As a result of generalizing the experience of 21 full packaged learning solutions, created by mathematics teachers and conversations with these teachers, we have identified six phases of creating a full packaged learning solution: concept; model; construct; technology; reflection; implementation and operation.

It is worth noting that the transition from the "reflection" phase in case of failure occurs to the "model" phase, otherwise to the sixth phase "implementation and operation".

Consider the actions performed in each phase.

Conceptual phase: formulation of the problem; identification of those who will take part; definition of the goal; selection of criteria; concept of solution.

Phase simulation: building a model (the image of a future solution); creating a model; approbation; optimization of the model (checking the model for stability under possible conditions changes); independent examination; choice of model.

Design phase: decomposition of the full packaged product into parts; aggregation (joining parts into a whole); study of conditions of use; description of the construct of the solution;

Technological phase: taking into account system of conditions, forms, methods, tools and criteria for creating a full packaged solution.

Reflective phase: final self-assessment; comparison of the result with the goal; expertise with the involvement of independent experts; evaluation of the experience gained by the development team.

Implementation and operation phase: implementation of the solution; support of the decision; upgrade solution.

Thus, the phases considered reflect all the elements of work on a full packaged learning solution from the origin of the idea to its actual implementation into mass production with further exploitation.

\section{Reflective Analysis of Using Full Packaged Learning Solutions}

To assess the effectiveness of using full packaged learning solutions in 2016-2017, there were 21 teachers of mathematics of different classes from four schools of the Kirov region - regional innovation sites, supervised by Vyatka State University. Teachers were encouraged to apply full packaged learning solutions developed by other colleagues during the lessons. After that, a questionnaire was proposed for self-assessment of the innovations presented. The reflexive question was: Estimate the average time spent on studying the lesson stages in minutes without using full packaged learning solutions and using them. The summarized results in minutes are presented in Table 1. 
Table 1. Results of a survey of respondents on a reflexive issue

\begin{tabular}{lcc} 
Preparation for the lesson & $\begin{array}{c}\text { Average estimate } \\
\text { of respondents' } \\
\text { time consumption } \\
\text { in minutes without } \\
\text { using full packaged } \\
\text { learning solutions }\end{array}$ & $\begin{array}{c}\text { Average estimate of } \\
\text { respondents' time } \\
\text { consumption in } \\
\text { minutes using full } \\
\text { packaged learning } \\
\text { solutions }\end{array}$ \\
\hline $\begin{array}{l}\text { 1. Purpose: definition of goals and objectives of the lesson } \\
\text { 2. Designing the content of the lesson and its competence interpretation }\end{array}$ & 5 \\
\hline $\begin{array}{l}\text { 3. Choice of the type of the lesson, form of organizing the cognitive activity of } \\
\text { students in class }\end{array}$ & 17 & 12 \\
\hline $\begin{array}{l}\text { 4. Definition of methods and tools of training, conditions for practical testing } \\
\text { of methods of activity, practical experience of using the acquired knowledge } \\
\text { and skills. }\end{array}$ & 5 & 4 \\
\hline $\begin{array}{l}\text { 5. Selection and preparation of the teaching and methodical support of the } \\
\text { lesson. }\end{array}$ & 22 & 4 \\
\hline $\begin{array}{l}\text { 6. Definition of techniques for receiving feedback, conducting reflection of } \\
\text { employment, checking and evaluating the results achieved by students. }\end{array}$ & 5 \\
\hline 7. Documentation of the results of the design of the lesson & 5 \\
\hline
\end{tabular}

Note that the results of the analysis of teachers' profiles show a $22 \%$ reduction in time spent on preparing for lessons. In addition, a hypothesis was tested on the equality of the general averages in the Student's t-criterion. Calculations showed that the experimental value of the criterion $\mathrm{T}$ fell into the critical region $\mathrm{T} \geq \mathrm{tkp}$, so the general averages of the two samples are not equal. Thus, it can be argued that the use of full packaged learning solutions significantly reduces the time spent on organizing the educational activities of students.

\section{Possible Marketplace for Maths}

Based on the research results in the marketplace for mathematics, it is advisable to distinguish three types of learning solutions: adjustable, integrated and full packaged.

Let's look at examples of learning solutions that make up the market for math.

- adjustable aearning solutions:

- library of abstracts;

- library of tests;

- didactic games;

- thematic pages of methodical schools;

- cards with tasks;

- other user-generated content.

Integrated learning solutions:

- e-courses;

- internal / remote micro-education;

- educational programs.

Full packaged learning solutions:

- a distance learning platform with a developed course of studies in the area of school mathematics;

- methodical instructions for conducting lessons of mathematics in primary school with a robotic designer (developed by the author of the article with teachers of experimental schools);

- methodical instructions for conducting lessons of mathematics in the main school with the use of tasks that involve calculating and measuring exercises with a set of calculating and measuring equipment (developed by the author of the article with teachers of experimental schools).

It should be noted that full packaged solutions are characterized by an object-development environment, which often should be added to existing integrated solutions with analysis of the integrity of software and methods. 


\section{DISCUSSIONS}

In the course of the research, we have achieved the following results: identified and systematized existing types of learning solutions (adjustable, integrated); the evaluation of the effectiveness of these types of training solutions has shown a high time-base for their use in preparing for classes; justified the allocation of a full packaged learning solution as a separate type of learning solution, defined and discussed with the professional community development stages and phases of creating full packaged learning solutions for studying mathematics with the aim of finding possible ways to reduce the workload of teachers and increase the quality of the educational results.

An experimental study was conducted to evaluate the effectiveness of using full packaged learning solutions on the basis of four schools in the Kirov region - regional innovation sites supervised by the Vyatka State University. The results of the analysis of teachers questionnaires show a $22 \%$ reduction in time costs on preparing for lessons using full packaged learning solutions. Experienced teaching on the developed full packaged learning solutions was carried out: comparison of numbers; geometric figures; straight, segment, broken line; solving simple problems on difference comparison; time and unit of time; solving problems for a multiple comparison; solving problems with proportional quantities; speed and others. Full packaged learning solutions included methodical instructions for conducting lessons with a robotic designer or using tasks that involve calculating and measuring exercises with a set of calculation and measuring equipment.

On the one hand, this approach allowed to generalize the experience of developing learning solutions (adjustable and integrated), to allocate a new type of full packaged learning solutions and to systematically present information about them for inclusion in the educational marketplace of math lessons. On the other hand, the generalization of the learning solution to the level of universality can lead to the loss of its customization. Customization in education is the correspondence of the educational solution to the tasks facing the future user. The higher the level of customization, the more specialized the learning solution is and thus the circle of potential users, which forces the professional community to develop a learning solution in proportion to the level of customization. Thus, full packaged solutions should be inherent in low customization for the universality of the proposed solutions and the application for learning by the widest possible number of students. The analysis of the level of customization of full packaged learning solutions and the time costs for their use by teachers can be further investigated.

Another aspect to be discussed is the determination of the choice factors of learning solution type used in mathematics. So, the factors can be: objectives of learning solutions, number of students, level of customization, degree of availability of necessary resources, and more. Determination of effective factors can allow to determine the optimal ratio of the types of learning solutions used in the practice of the mathematics teacher and organize work on the transition to low time-consuming means of preparing teachers for lessons.

\section{CONCLUSION}

Thus, a significant result of the research is the theoretical justification of full packaged learning solutions as a separate type of learning solutions for studying mathematics. The description of full packaged learning solutions allows to organize the work of a step-by-step transition from the development of adjustable to full packaged learning solutions. Full packaged solutions help to reduce the time spent by math teachers on preparation for classes. The full packaged learning solution is considered to be a package of program-methodical and subjectdeveloping support that can be used by consumers of educational services (children, parents, teachers, administrators, employers) for independent use (turn-key project). In general, we can identify the two key indicators of full packaged learning solutions, which essentially distinguish them from other types of learning solutions. The first indicator is that the economic feasibility of using such solutions is in most cases higher than that of adjustable and integrated solutions. It is achieved through the transfer of all the work necessary for the introduction of the practice of a general education organization and additional resources are no longer required. The second indicator is related to methodical effectiveness. Learning solutions that have predictable financial costs, time parameters and a great list of works on its implementation make it possible to approximate the achieved educational results to the results set by the solution developer. Therefore, predictability of quality is a key indicator of the full packaged solution. It is worth noting that the time spent on implementing a full packaged learning solution is determined by the willingness of the mathematics teacher to adopt the implemented solution, and here a special role belongs to the head of the general education organization.

The differentiation of learning solutions allows to consider the educational marketplace of mathematical lessons through three components: adjustable, integrated and full packaged solutions. Each component has its own performance indicators. The rational combination of the components of the educational marketplace of lessons in mathematics makes it possible to organize an effective management of the pedagogical process. 
Stages of development and phases of creating a full packaged learning solution will allow to build a process for identifying and creating full packaged solutions in the practice of educational organizations with their subsequent replication.

\section{ACKNOWLEDGEMENT}

1. The work is performed according to the Russian Government Program of Competitive Growth of Kazan Federal University.

2. The publication has been prepared with the support of the "RUDN University Program 5-100".

\section{REFERENCES}

Akpinar, I. A. (2012). The effect of 5e learning model on pre-service science teachers' achievement in the subject of solutions. Energy Education Science and Technology Part B: Social and Educational Studies, 4(2), 867-874.

Bandura, A. (2001). Social cognitive theory: An agentic perspective. Annual Review of Psychology, 52(1), 1-26. https:/ / doi.org/10.1146/annurev.psych.52.1.1

Bereza, N. V. (2012). "Modern trends in the development of the world and Russian information services market". Retrieved from http:/ / cyberleninka.ru/article/n/sovremennye-tendentsii-razvitiya-mirovogo-i-rossiyskogo-rynkainformatsionnyh-uslug

Bloom, B. (1984). The 2 Sigma Problem: The Search for Methods of Group Instruction as Effective as One-to-One Tutoring. Educational Researcher, 13(6), 4-16. https:/ / doi.org/10.3102/0013189X013006004

Bokovoi, Yu. V. (2006). Peculiarities of the methodology of designing information systems for small and mediumsized businesses. Applied Informatics, 5, 3-11

Bordovsky, G. A. (2012). Challenges of modern education system to a schoolteacher. Vocational Education in Russia and Abroad, 6, 6-10

Carapina, M., Mekterovic, I., Jagušt, T., Drljevic, N., Baksa, J., Kovacevic, P., \& Boticki, I. (2015). Developing a multiplatform solution for mobile learning. Paper presented at the Proceedings of the 23rd International Conference on Computers in Education, 384-389. Retrieved from www.scopus.com

Dewey, J. (1937). Experience and education. New York: Simon and Schuster. https://doi.org/10.1111/j.21516952.1998.tb00812.x

Doolan, M., \& Guiza, M. (2015). Towards a novel methodology for adopting blended collaborative learning solutions. Paper presented at the Proceedings of the International Conference on e-Learning. ICEL, 2015-January 83-90. Retrieved from www.scopus.com

Dover, P. A., Manwani, S., \& Munn, D. (2018). Creating learning solutions for executive education programs. International Journal of Management Education, 16(1), 80-91. https:/ / doi.org/10.1016/j.ijme.2017.12.002

Durkin, K., Star, J. R. \& Rittle, J. B. (2017). Using comparison of multiple strategies in the mathematics classroom: Lessons learned and next steps. ZDM - Mathematics Education, 49(4), 585-597. https:/ / doi.org/10.1007/s11858-017-0853-9

Feldshtein, D. I. (2010). Priority directions of psychological and pedagogical research in conditions of children development significant changes. Pedagogy, 7, 3-11.

Fiallo, J., \& Gutiérrez, A. (2017). Analysis of the cognitive unity or rupture between conjecture and proof when learning to prove on a grade 10 trigonometry course. Educational Studies in Mathematics, 96(2), 145-167. https:/ / doi.org/10.1007/s10649-017-9755-6

Govindarajan, K., Kumar, V. S. \& Kinshuk, A. (2017). Dynamic learning path prediction - A learning analytics solution. Paper presented at the Proceedings - IEEE 8th International Conference on Technology for Education. T4E 188-193. https:// doi.org/10.1109/T4E.2016.047

Heider, J. S. (2015). Using digital learning solutions to address higher Education's greatest challenges. Publishing Research Quarterly, 31(3), 183-189. https:/ / doi.org/10.3102/003465430298487

Herzog, M., Ehlert, A., \& Fritz, A. (2017). Combinatorial problems in Grade 3: Influences of representation, level of abstraction and use of strategies on solving success. Journal Fur Mathematik-Didaktik, 38(2), 263-289. https:/ / doi.org/10.1007/s13138-017-0118-8

Hoffmann, T. (1999). Distance learning solutions. Journal of European Industrial Training, 23(6), 62-69.

Jensen, K., \& Frimodt-Møller, S. (2015). An integrated playful music learning solution. Retrieved from http://vbn.aau.dk/en/persons/kristoffer-jensen(1ff9e3d6-ce36-45e7-85fa-f8d4cc07129d)/cv.html?id= 45857323 https://doi.org/10.1007/978-3-319-20684-4_45 
Kenttälä, V., Rousi, R., Kankaanranta, M., \& Pänkäläinen, T. (2015). Usability challenges in digital learning solutions. Paper presented at the Proceedings - Frontiers in Education Conference. FIE, 251-254. https://doi.org/10.1109/FIE.2015.7344053

Kvon, G. M., Lushchik, I. V., Karpenko, M. A., Zaitseva, N. A., Kulkov, A. A., Galushkin, A. A., \& Yakupova, N. M. (2017). Regional investment policy: Analysis and assessment of the investment environment state. Eurasian Journal of Analytical Chemistry, 12(5), 835-853. https:/ / doi.org/10.12973/ ejac.2017.00215a

Lave, J., \& Wenger, E. (1991). Situated learning: Legitimate peripheral participation. Retrieved from: http://qvole.org/comm146/undergrdpgs/plee1/pris/Postings/Entries/2013/3/16_Eventology(WI_13)_ files/lave.pdf https:/ / doi.org/10.1525/ae.1994.21.4.02a00340

Matad, N. A., Srinivasa, K. G., \& Fernandes, L. (2016). Vidhya sangam: A cost-effective video learning solution for class-room and students personal use. Paper presented at the ICCE 2016 - 24th International Conference on Computers in Education: Think Global Act Local - Workshop Proceedings, 316-321. Retrieved from www.scopus.com

Molnar, M. (2014). Richard Culatta: Five Ways Technology Can Close Equity Gaps. Retrieved on September 21, 2015, from http://blogs.edweek.org/edweek/marketplacek12/2014/11/richard_culatta_five_ways_technology _can_close_equity_gaps

Niemelä, P., Isomöttönen, V., \& Lipponen, L. (2016). Successful design of learning solutions being situation aware. Education and Information Technologies, 21(1), 105-122. https:/ / doi.org/10.1007/s10639-014-9311-2

OECD (2015), Students, Computers and Learning: Making the Connection, PISA, OECD Publishing. https:/ / doi.org/10.1787/9789264239555-en

Payne, A. M., Stephenson, J. E., Morris, W. B., Tempest, H. G., Mileham, A. \& Griffin, D. K. (2009). The use of an elearning constructivist solution in workplace learning. International Journal of Industrial Ergonomics, 39(3), 548-553. https://doi.org/10.1145/1362550.1362577

Reimagining the Role of Technology in Education. (2017). National Education Technology Plan Update. U.S. Department of Education. Retrieved from https:/ / tech.ed.gov/files/2017/01/NETP17.pdf

Scanlon, M., \& Buckingham, D. (2004). Home learning and the educational marketplace. Oxford Review of Education, 30(2), 287-303. https:/ / doi.org/10.1080/0305498042000215575

Shaidullina, A. R., Krylov, D. A., Sadovaya, V. V., Yunusova, G. R., Glebov, S. O., Masalimova, A. R., \& Korshunova, I. V. (2015). Model of Vocational School, High School and Manufacture Integration in the Regional System of Professional Education. Review of European Studies, 7(1), 63-67. https:/ / doi.org/10.5539/res.v7n1p63

Sommer, T., Bach, U., Richert, A., \& Jeschke, S. (2014). A web-based recommendation system for engineering education e-learning solutions. Paper presented at the Proceedings of the International Conference on e-Learning. ICEL, 169-175. Retrieved from www.scopus.com. https:/ / doi.org/10.15680/IJIRSET.2014.0309049

Spitzer, B. \& Aronson, J. (2015). Minding and mending the gap: Social psychological interventions to reduce educational disparities. British Journal of Educational Psychology, 85(1), 1-18. https:/ / doi.org/10.1111/bjep.12067

Swacha, J. (2017). Exercise solution check specification language for interactive programming learning environments. Paper presented at the OpenAccess Series in Informatics, 6, 5610.4230. https:// doi.org/10.4230/OASIcs.SLATE.2017.6

Trunovich, A. S., \& Shlygin A. S. (2008). Competence approach in the management of organization's human resources. Statistics and economics, 2, 263-275. Retrieved from http:/ / cyberleninka.ru/article/n/kompetentnostn-yy-podhod-v-upravlenii-chelovecheskimi-resursamiorganizatsii

Viel, C. C., Rodrigues, K. R., Teixeira, C. A., \& Pimentel, M. G. (2015). Design solutions for interactive multi-video multimedia learning objects. Learning and Collaboration Technologies, 10, 160-171. https://doi.org/10.1007/978-3-319-20609-7_16

Vinogradova, E. Yu., \& Galimova, A. I. (2017). Principles of a corporate information system formation for implementation at Russian enterprises. Izvestiya Ural State University of Economics and Management, 2(70), 111-123. https:/ / doi.org/10.29141/2073-1019-2017-14-2-10

Zolotov, E. (2013). By a wave of a wand. Business Journal, 3(204), 50-54.

\section{http://www.ejmste.com}

